dit met haere respective handteekeningen bevestigt desen 25en Augustus 1668; was geteeckent by de regenten ofte gebieders, hier bovengemelt, ende den ondercoopman Jan de Harde.

\title{
CCCXXIII. BANDA.
}

\section{Juni-2 Juli $1668 .{ }^{1}$ )}

De fluit Loenen en de sloep Walingen gingen voort, volgens de instructie van den gouverneur van Banda Cops, de verhoudingen te regelen met de Zuidwaarts gelegen eilanden, o.a. met de Zuidwester-eilanden Leti, Moa en Lakar 2). Onderlinge oneenigheden van de hoofden dier eilanden maakten onder meer regeling der verhoudingen noodig.

I.

Cort ende kennelijk sij een ijgelijk, dies aangaande, dat wij, afgesanten gesonden uijt den naam van den E. Heer Jacop Cops, raad extra-ordinaris van India, gouverneur en directeur der eijlanden Banda en aancleven van dien, onder het beleijt van den $\mathrm{Ed}^{\mathbf{e}}$ Heer Joan Maatsuijcker, gouverneur generaal over gants Nederlants Orienten, representerende den staat van de Verenigde Nederlantsche Oostindische Compagnie, ter eenre, ende de orangcaijs op 't eijlant

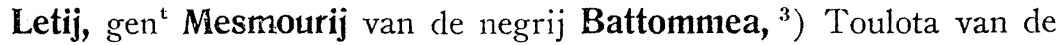
negrij Touttekaij ${ }^{4}$ ) ende Soweleekij van de negrij Lovelullij, ${ }^{5}$ ) nevens hunne onderhorige ter andere sijde, het verbont van den 7e September $1662,{ }^{6}$ ) $29 \mathrm{e} \mathrm{Julij}^{7}$ ) en 10e December $1665^{6}$ ) tusschen gemelte $\mathrm{E}$. Compagnie ende hun orangkaijs opgerecht, niet alleen wederzijts vernieut maar oock noch daarenboven het selve in manieren als volgt voor eeuwig duierent vastgestelt, te weten.

Eerstelijck dat zij, orangcaijs, als opperste van alle de vordere orangcaijs van Letij, oock uijt den naam van hare successeuren en onderdanen beloven, d'E. Compagnie gehou en getrou te wesen, en

1) Uit het Contractboek.

2) Thans behoorende tot de residentie Timor.

3) Volgens Veth, Woordenboek, I, bldz. 120 ligt Batoe Meauw aan de Oostkust. „Men treft er de vrij groote ruine van een Nederlandsch fort aan”.

4) Zie hiervóór, bldz. 331 .

5) ?

6) $\mathrm{Mij}$ onbekend.

7) Zie hiervóór, bldz. 332 . 
dat sij niet sullen gedogen, dat enige Engelse, ${ }^{\mathbf{1}}$ ) Portugesen, ${ }^{\mathbf{2}}$ ) of Macassaren ofte enige andere vaartuijgen, dewelcke met d'E. Compagnie in oorlog zijn, aan dit haar eijlandt sullen mogen comen, en bij aldien eenige sodanige vaartuigen quamen, deselve sullen vijandelijk aantasten ende bij veroveringe van dien deselve gevangen houden totter tijt enige vaartuigen van d'E. Compagnie comen, en als dan de gevangenen, t'zij Portugesen of Macassaren, overleveren, om in handen van de E. Compagnie te geraacken.

Waarvoor wij ondergeschreven weder beloven, aan bovengenoemde orangkaijs Mismourij, Toulota en Sawelekij uijt den naam van de $\mathrm{E}$. Compagnie, dat wij haarlieden voor sooveel gevangene als sij aan d'E. Compagnie soude mogen overleveren, sullen te vrede stellen met sodanige vereringe, als bij den E. Heer Gouverneur in Banda sal geoordeelt werden te behoren.

De voorschreven orangkaijs beloven oock, datse alle vaartuijgen van de Compagnie alhier op haar rhede comende, in alle gelegentheden de behulpsame hant sullen bieden, hetzij met verversinge, water ofte andere behoeftigheden, die deselve benodigt mogte zijn en voornamentlijck met haar te negotieren in alle vruntschap met sodanige coopmanschappen, als op hun eijlant d'E. Compagnie dienstigh en aldaar sullen mogen bevonden werden.

Ten laatsten en voornamentlijck beloven de voornoemde orangkaijs, bijsonder orangkaij Sowelekij, in welckers negrij den orangkaij Backer ${ }^{3}$ ) noch een hondert negen en dertigh Makisseresen op onse aankomste gevonden heeft en in die van orangkaij Mesmourij thien $\mathrm{d}^{\text {s }}$, datse niet alleen deselve, maar noch alle, die na desen noch sullen op haar lant gevonden werden, dewelcke jongst door ons, de Portugesen van Larrentoucke alhier ontjaacht zijn, naar ons vertreck van hier aan den orangkaij Backer getrouwelijck tot den laatsten man toe sullen weder overleveren, om also op haar eijgen lant, van waar sij gerooft zijn, weder gebragt mogen werden.

In tegendeel belooft d'E. Compagnie, bij aldien wij, orangcaijs, nevens hare ondersaten de voorverhaalde artijculen poinctuelijck na te komen, de bescherminge over haar aan te nemen, tegens alle haare

1) Reeds 31 Juli 1667 was de vrede te Breda tusschen Engeland en de Republiek gesloten.

2) Dat vooral tegen de Portugeezen werd gewaarschuwd, zal óók verband houden met de gebeurtenissen in Makassar.

i) Zie hiervóór, bldz, 329 enz. 
vijanden de behulpsame hant te bieden ende getrouwelijk bijstant te bethoonen.

Tot dien einde hebben zij, orangkays, ons met gewoonlijcke eetsweringe dit wederzijts bevestigt en hebben den orangkaij Sawelekij, omdat zijn vlagge van d'E. Compagnie door de Larentoukse ontrooft is, wederom een nieuwe in de plaatse vereert, om nevens andre bij verschijninge van onse natie te laten waaijen.

Actum in de fluijt Loenen, g'anckert leggende voor Letij op de rhede van de negrij Toutekaij, desen $25^{\mathrm{e}}$ Junij 1668. Onderstont: gestelt bij orangkaij Taulata, gestelt bij orangkaij Sawelckij. Was getekent Maarten Roos, gestelt bij Gillis Duijnmeijer, Jan Blinne, Jan Panne.

II.

Cont ende kennelijk sij een ijgelijk, dies aangaande, dat wij, afgesanten, gesonden uijt den naam van den E. Heer Jacob Cops, Raat extraordinaris van India, Gouverneur en Directeur der eijlanden Banda etc ${ }^{\circledR}$, onder het beleijt van den Ed. heer Joan Maatsuijcker, gouverneur generaal over gants Nederlants Orienten, representerende den staat van de gantsche Nederlantsche Geoctroijeerde Oostindische Compagnie ter eenre, en den orangkaij van de negrij Pattij, genaampt Tettij, residerende op 't eijlant Moa, nevens zijn onderhorige ter andere zijde, het verbont tusschen hem en d'E. Compagnie opgerecht in dato $6^{e}$ December $A^{\circ} .1665^{1}$ ) niet alleen bij desen wederom vernieut, maar oock voor eeuwig duierent in manieren als volgt hebben vastgestelt.

Eerstelijck belooft hij, orangkaij Tettij, nevens zijne ondersaten haar te sullen ${ }^{2}$ ) tot getrouwe onderdanen van de $\mathrm{Ed}^{\mathrm{e}}$ Nederlantse Oostindise Compagnie, die te erkennen alleen voor haar heer en meester, onder wiens gebiet en protexie (naest Godt) sij haar zijn begevende.

1) $\mathrm{Mij}$ onbekend. - Zie ook noot 3 op bldz. 331.

2) Stellen? 
Ten tweede dat alle coopmanschappen, t'zij slaven, wasch, schilpatshoorn ofte yets anders, d'E. Compagnie gading zijnde, de selve aan d'E. Compagnie voor een redelijcke prijs te sullen verhandelen.

Ten derden dat met geen, hetsij blancke ofte swarte, natie, gelijck als Engelse, Portugesen, Maccassaren, Maleijers, Javanen of Cerammers, ofte enige andere vreemde natie, die in oorlogh met d'E. Compagnie mogte sijn, ofte hier namaals comen, sullen handelen, dan alleen met hooggemelte Nederlantsche Oostindische Compagnie, maar integendeel van hun lant en strant af te wijsen, soo veel haar bij onse absentie doenelijck sal wesen.

Daarentegen en ten vierden, soo belooft d'E. Compagnie, indien hij, orangkaij Tettij, en sijn onderhorige de drie voorschreven artijkulen nacomen, tegens alle haare vijanden de behulpsame hant te bieden ende trouwelijck bijstant te bethonen.

Tot dien eijnde heeft hij, orangkaij, voor desen 's Compagnie steen en vlagge ontfangen, oin deselve bij verschijninge van onse Hollantsche natie te thonen en te laaten waaijen.

En dit beijdersijts sal naargekomen werden, hebben desen met onse gewoonlijke eetsweeringe aan wedersijts bevestigt.

In de fluijt Loenen g'anckert leggende voor 't eijlandt Mowa, bij de negerij Jesette ${ }^{1}$ ), den $29^{\circ}$ Junij 1668 . Was getijckent: gemerckt bij orangkaij Tettij, gemerkt bij orangkaij Malpe, gestelt bij orangkaij Rautouta, gemerckt bij orangkaij Rakau, Marten Roos, gestelt bij Gillis Duijnmeijer, Jan Blinne en Jan Panne.

III.

Cont en kennelijck sij een ijgelijk, dies aengaende, dat wij, afgesanten uijt den naam van den E. Heer Jacob Cops, Raat Extraordinaris van India, mitsgaders gouverneur en directeur der eijlanden Banda, onder het beleijt van den $\mathrm{Ed}^{\circ}$ heer Joan Maatsuijcker, gouverneur generaal over gants Nederlants Orienten, representerende den staat van de Nederlantsche g'octroyeerde Oostjindische Compagnie ter eenre, ende de orangkays Roijwacka, Loisive en Jorlijt van de

1) ? 
negrij Nannoulij ${ }^{1}$ ) op 't eijlandt Laccar, ${ }^{2}$ ) nevens hunne onderhorige ter andere zijde, het verbont tusschen d'E. Compagnie en hun in dato $4^{\text {e }}$ Aug. $1665^{3}$ ) opgerecht, bij desen wederom vernieuwen en voor eeuwigh duirende oprechten in manieren als volght.

Ten eersten beloven sij, orangkaijs, nevens haare ondersaten haar te stellen tot getrouwe onderdanen van d'E. Nederlantsche Oostindische Compagnie, die te erkennen voor haar heer en meesters, onder welckers gebiet en protexie (naest Godt) sij haar sijn begevende.

Ten tweeden dat alle coopmanschappen, het sij slaven ofte wat onder haar gebiet d'E. Compagnie dienstigh zijnde te bekomen, sij d'selve aan d'E. Compagnie voor een redelijcke prijs te sullen verhandelen.

Ten derden dat met geen andere natie, gelijck Engelse, Portugesen, Macassaren, Cerammers, ofte enige andere, die met d'E. Compagnie in oorlogh souden mogen sijn, ofte hier namaals comen, sullen handelen, dan alleen met gemelte Nederlantsche Oostindische Compagnie, maar in tegendeel haar van hun lant en strant afwijzen en haar alle verversinge, water en andere behoeftigheden ontseggen en weder doen vertrecken, sonder haar enigsints de behulpsame hant te bieden. En bij aldien eenige Portugesen ofte Macassaren etc. tegens hun danck wilden landen, sullen deselve soo mogelijk trachten te vermeesteren en gevangen nemen tottertijt onse natie arriveert, aan welcke zijde sijluijden d'selve sullen overleveren tegens soodanige vereeringe als den E. Heer gouverneur in Banda daartoe sal ordineren.

Ten vierden soo belooft de $\mathrm{E}$. Compagnie in tegendeel, indien sij Lackeresen de drie voorschreven artijckulen poinctuelijck naarcomen, de bescherminge over haar aan te nemen en tegens alle haar vijanden de behulpsame hant te bieden.

Toirconde desen hebben wij weder wedersijts dit verbont met onse gewoonelijcke eetsweringe bevestigt. In de chialoup Walingen, leggende geanckert voor de negrij Orwane ${ }^{4}$ ) op 't eijlant Lacker, desen

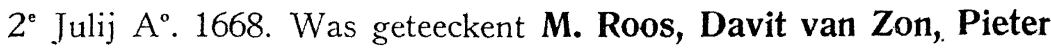
Adriaensen. Gestelt bij orangkaij Loisive, gestelt bij orangkaij Jorseijt.

1) Een negerij Nanloeli ligt op Leti. (Veth, II, bldz. 547).

2) Lakor.

3) Zie hiervóór, bldz. 332.

4) ? Zie bldz. 332, v. 